\title{
Reliability Optimization in the Islanded Mode of Microgrid
}

\author{
Sundari Ramabhotla, Stephen B. Bayne, Tyler J. Flack and Michael Giesselmann \\ Department of Electrical \& Computer Engineering, Texas Tech University, Box 43102, Lubbock, TX 79409-3102, USA
}

Received: September 23, 2016 / Accepted: October 11, 2016 / Published: February 28, 2017.

\begin{abstract}
A microgrid is a combination of distributed energy resources and controllable loads. The main objective of this research is to optimize energy flow within a microgrid with regards to reliability in grid connected mode. A microgrid with combined heat and power, natural gas generator, diesel generator, solar energy, wind energy, and battery energy storage along with a critical load is considered in this research. An event oriented analytical method called FTA (fault trees analysis) is implemented for reliability optimization using PTC Windchill Solutions software in a microgrid. The reliability of each component in each energy source of the microgrid is calculated using FTA. The reliability of the critical load is evaluated. The quantitative and qualitative results of FTA are evaluated in order to interpret the results of fault tree. The sensitivity and uncertainty of the fault tree results for critical load is deduced by calculating the importance measures such as risk achievement worth, risk reduction worth, criticality importance and Fussel-Vesely importance. Finally from the results the components that are sensitive and at high risk are deduced.
\end{abstract}

Key words: Fault trees analysis, microgrid, reliability, importance measures, critical load, quantitative and qualitative analysis.

\section{Introduction}

Recently, the concept of a microgrid emerged as a viable solution to the technical and economic concerns associated with blackouts in traditional power systems [1]. A microgrid may be defined as a small-scale power system, which operates with respect to the main grid, by integrating DERs (distributed energy resources) close in proximity to user loads. Additionally, microgrid has two distinct modes of operation, namely grid connected and islanded modes. Due to the presence of transmission/distribution fault, the microgrid shifts from grid connected mode to an islanded mode. In an islanded mode, the power is supplied to the critical load and the microgrid disconnects from the main grid. Some benefits of a microgrid include increased reliability, low cost operation, and a reduced environmental impact. These benefits of a microgrid have attracted significant

Corresponding author: Sundari Ramabhotla, Ph.D., instructor, research fields: power systems, renewable energy, microgrids. research attention in recent years. A microgrid is connected to the main grid through a PCC (point of common coupling). The overall performance of a microgrid is affected by reliability and adequacy of DERs. For effective evaluation of the reliability of a microgrid system, indices like failure rate, repair time, and load unavailability are defined for use [2].

Few researchers have investigated the impact of reliability on microgrids operating in islanded mode [3, 7]. Overall microgrid performance is affected by the reliability and adequacy of DERs. In Ref. [4], a microgrid with PV, wind turbine, and other DERs is considered and sequential Monte Carlo method is implemented to study reliability of the microgrid. The reliability indices calculation helps to optimize the reliability of the microgrid. In Ref. [5], economic issues, reliability, and establishment/quality of energy, are discussed in a microgrid with solar and wind generation and the reliability indices are calculated to evaluate the reliability of a microgrid with the help of the minimal path method. By integrating the 
microgrid with stochastically distributed generators, evaluation of microgrid reliability is performed using a new method as proposed in Ref. [5]. This paper proposes a new approach to evaluate and optimize reliability of a microgrid in islanded mode, using FTA (fault tree analysis). The reliability and availability of the outage of critical load is calculated with the help of PTC Windchill solutions software. Components at higher risk of reducing reliability are identified by calculating of using importance measures, this serves to optimize the reliability.

\section{Reliability Optimization Using FTA Method}

FTA is defined as an event oriented analytical technique in which an undesired state of a system is first specified, and then evaluated in the context of its environment and operation; the goal is to find all realistic ways in which the undesired event may occur. In a system, the critical state or failure with respect to the safety or reliability is specified by the undesired state. The undesired state of a component is considered as a top event in a fault tree and analyzed further for evaluation of reliability $[2,12]$.

FTA is a deductive, top-down approach, which combines graphical models with qualitative and quantitative analysis. It includes probabilistic failure data with corresponding results associated with it. The qualitative analysis includes minimal cut sets, which represent the smallest events which can lead to the occurrence of the top event. The quantitative analysis determines the cause(s) for the occurrence of a top event and any other events when basic events probabilities are provided. Several parallel and sequential combinations of faults are represented by a graphical model. This will further lead to the top event occurrence which consists of a pre-defined undesirable event $[2,5,12,31]$.

In a fault tree construction, logic gates connect primary events to the top event [28]. Primary events consist of both basic events and house events. Basic event, denoted by a circle, is a final part of the fault tree that consist of the undesired events as well as their failure modes [12]. An OR gate or an AND gate is used to start a top event for the FTA. Top events include the description, identification code, and sign denoting the logic gate. In the fault tree, when all the inputs occur at the same time, an AND gate is used to represent the output event, while OR gate is used for the output event, if any one of the input occurs. When there is not sufficient information to develop an event further, an undeveloped event is used [2]. The system's failure mode is denoted by the top event which is evaluated by its components and influence factors $[2,12]$.

\subsection{Qualitative Fault Tree Evaluation}

Qualitative fault tree evaluation is a method to find the combinations of basic events which cause the top event to occur. For a fault tree in the form of Boolean logic equations, Boolean algebra rules are applied to obtain full equation(s) for the top event. The result(s) obtained will be in the form of a sum of products of basic events [2].

MCS (minimal cut sets) represent the components failures which cause failures in the system [31]. An MCS may be acquired from the sum of products obtained from the combinations of basic events. A single MCS contains only one basic event, this implies that the system failure is caused by a single component. Similarly an MCS may contain $n$ number of basic events. From all basic events, basic event probabilities are evaluated when the probabilistic data is assigned for each basic event. From the FTA, MCS is generated to find the basic event probabilities.

\subsection{Quantitative Fault Tree Evaluation}

In a fault tree, the basic event denotes the final part of the fault tree. The probability a top event occurring is calculated using the probabilities of a basic event occurrence. Hence, the quantitative analysis is the top event probability which represents the system failure 
probability. The equation for the quantitative analysis is given below in Eq. (1) as:

$$
\begin{gathered}
P_{T O P}=\sum_{i=1}^{n} P_{M C S_{i}}-\sum_{i<j} P_{M C S_{i} \cap M C S_{j}} \\
+\sum_{i<j<k} P_{M C S_{i} \cap M C S_{j} \cap M C S_{K}}-\cdots \\
+(-1)^{m-1} P \bigcap_{i=1}^{m} M C S_{i}
\end{gathered}
$$

where, $P_{T O P}$ is the top event probability of the fault tree; $P_{M C S_{i}}$ is the probability of occurrence of minimal cut set $i\left(M C S_{i}\right), n$ is the number of minimal cut sets, $m$ is the number of basic events in the largest minimal cut set $[2,3,12]$.

The probability of the minimal cut sets $P_{M C S_{i}}$ is given as:

$$
\begin{gathered}
P_{M C S_{i}}=P_{B 1} \times P_{B 2}\left|P_{B 1} \times P_{B 3}\right| P_{B 1} \\
\cap P_{B 2} \times \ldots \times P_{B m} \mid P_{B 1} \cap P_{B 2} \\
\cap \ldots \cap P_{B m-1}
\end{gathered}
$$

where parameters $P_{B 1}, P_{B 2}, \ldots, P_{B n}$ denote the failure probabilities of basic events $B 1, B 2, \ldots, B n$, respectively. The probabilistic model is used to calculate the probabilities of each basic event. PTC Windchill Solutions simulation software is used to perform the quantitative analysis $[2,31]$.

\subsection{Results}

The top event of the FTA consists of occurrence of a critical load outage. A fault tree is constructed for critical load outage and analyzed further for the reliability optimization. Fig. 1 illustrates the architecture of the microgrid test bed used. With the help of PCC, the microgrid is connected to the maingrid. The microgrid operates in two modes: grid connected mode and islanded mode of operation. In the grid-connected mode, through the help of PCC the microgrid is connected to main grid and the power flows between the maingrid and microgrid. While in the islanded mode of operation, the microgrid is disconnected from the maingrid and supplies power to the critical load. Microsource controller and central controllers coordinate and control the whole process.

In Fig. 1 the microgrid comprise of DERs and loads connected to the main grid. The DERs like CHP (combined heat $\&$ power), a natural gas generator, a

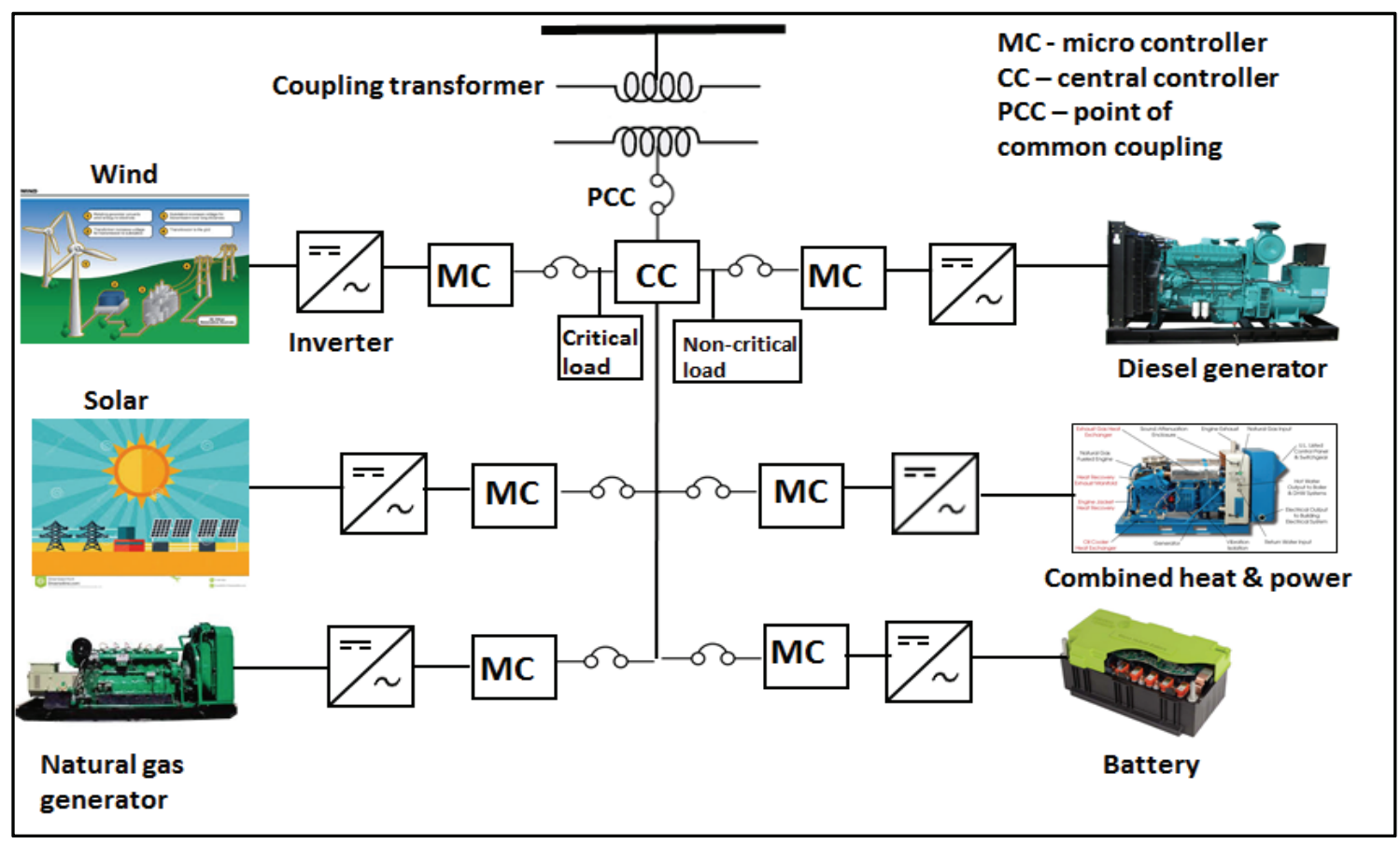

Fig. 1 A microgrid integrated with energy sources and loads. 
diesel generator, solar energy, wind energy and a battery as energy storage with power ratings $1.5 \mathrm{MW}$, $1 \mathrm{MW}, 1 \mathrm{MW}, 500 \mathrm{~kW}, 500 \mathrm{~kW}, 500 \mathrm{~kW}$ is considered along with a critical load of $2.5 \mathrm{MW}$. The two generators and CHP are incorporated in the microgrid operation as spinning reserves. A lithium ion battery with a power rating of $500 \mathrm{~kW}$ is considered with a charge and discharge rates of $\mathrm{C} / 2$ and $\mathrm{C} / 3$ respectively. The battery charges and discharges for every 2 hours and 3 hours respectively. Accordingly, the total load will become 3 MW during the charging mode of the battery energy storage. Though all the renewable energy sources fail, still the two generators and CHP can supply power to the critical load. If either a generator or CHP fails, then the power supply to critical load fails.

\subsubsection{Fault Tree Analysis of a Critical Load}

A critical load outage of power rating 2.5 MW is considered and a fault tree is built using logic gates, as illustrated in Fig. 2. A critical load outage may occur due to failure in the microgrid or circuit breaker associated with the critical load. The intermediate gates of the circuit breaker and microgrid failures are transferred with the help of a transfer gate for easy understanding [2]. Fig. 2 shows a fault tree built for a critical load outage. "Q" denotes the failure probability of the respective component in each fault tree. The component failures are discussed in detail in below sections.

\subsubsection{Circuit breaker}

Failure of the critical load may occur due to failure of circuit breaker associated with the critical load.

Therefore it is important to evaluate circuit breaker failure when considering the critical load outage. A circuit breaker is present across each energy source. Therefore, the circuit breaker is considered as an important failure in the operation of microgrid.

Possible circuit breaker failures are: tripping (electromagnetic, bimetal strip bends); circuit becomes weak; overloaded circuit; locked in closed/open position; bus bar problem; circuit breaker opens/close on

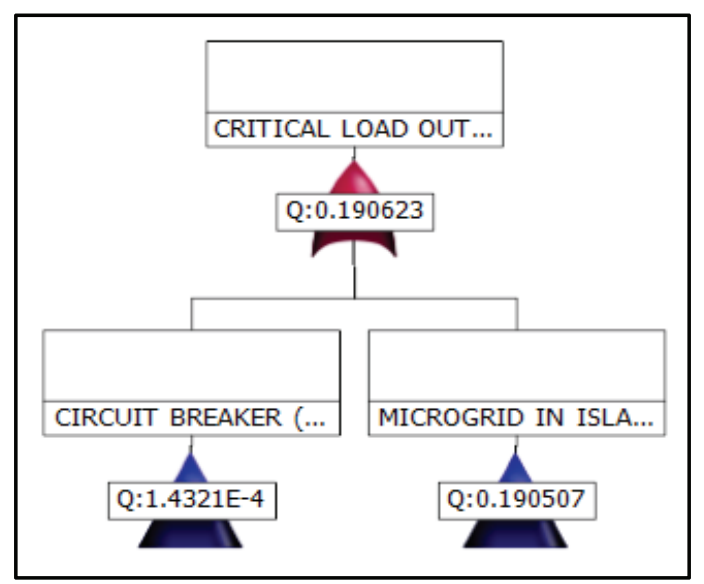

Fig. 2 Critical load outage.

command; circuit breaker open/close without command; fail to carry current; dielectric breakdown: breakdown to earth, internal breakdown across the open pole during the opening operation, across the open pole, breakdown between the poles; loss of mechanic integrity [2, 8-11, 29].

A fault tree is constructed for a circuit breaker based on primary secondary and basic failures of a circuit breaker. The intermediate events consist of primary failures. The failures which are classified in the primary failures are denoted by basic events. A fault tree is constructed with all the events and then evaluated to obtain the failure probability of a circuit breaker. The failure probability of a circuit breaker is obtained as $1.4321 \mathrm{e}-4$. The failures mentioned above are considered as the intermediate events and further classified to obtain the basic events and the failure of their respective failure probabilities are evaluated.

\subsubsection{Microgrid}

The next failure which may cause critical load failure is in the microgrid. The microgrid fails when its ability to meet the critical load fails. This type of failure may be due to failures in solar energy, wind energy, CHP, battery energy storage, diesel generator or natural gas generators. The microgrid failure occurs when all the DERs fail. A fault tree is constructed for the microgrid failure as shown in Fig. 3. The failure probability of a microgrid is obtained as 0.190507 . Each energy source is considered and classified 
further to obtain the failures across each energy sources. A transfer gate is used to transfer the failures in each energy source into separate fault trees [2]. These are described in subsequent sections of the paper. The failure probability for the intermediate and basic events of the microgrid are represented in Fig. 3.

\subsubsection{Solar energy}

Failures associated with solar energy will result in reduction of power generated in the microgrid, thus impacting the reliability of the microgrid. Solar energy failure can occur due to the failures in: circuit breaker across the solar energy, weather station, operated beyond the rated conditions, defective electrodes, inadequate design, communications, manufacturing quality defects, inverter $[13,14,30]$.

An inverter is power electronic system which converts DC voltage to AC voltage. So, it is employed in most of the energy sources to obtain AC voltage. In the year 2012, the MTBF (mean time between failures) of the average inverter is 12 years [13]. Failure modes of inverters are as follows: over current, over voltage, thermal shock, thermal overload, extremely cold operating conditions, control software, IGBT failure-fatal failures; high voltage breakdown; static dynamic latchup; second breakdown; energy shock, non-fatal failures - bond wires lift off; gate driver failure, thermal stress, ac stress, electric stress, overload occurrence [15]. Fig. 4 shows the fault tree for a solar energy [2]. The failure probability of the solar energy is obtained as 0.025609 and the failure probability for the intermediate and basic events of the solar energy are represented in Fig. 4. The fault tree for an inverter along with all the failures in each energy source is shown in Fig. 5. The failure probability of an inverter is obtained as 0.015774 and the failure probability for the intermediate and basic events of the inverter are represented in Fig. 5.

\subsubsection{Wind energy}

Due to the failure of the wind energy, the microgrid's power generation decreases which will impact the reliability of a microgrid. This will have an impact on the critical load. The circuit breaker across the wind energy also causes the wind energy to fail. Thus, the failures in the wind energy are [21-27]: technical failure-heating; grid connection; brakes; hydraulics; yaw system; rotor bearings; gear; generator; charge controller; control system; sensors; rotor blade; rotor hub; cables; main frame; main shaft; nacelle; pitch system; screws and tower; network disturbance, maintenance, minor disturbance, icing, circuit breaker across the wind energy, inverter. The fault tree of the wind energy is shown in Fig. 6 [2]. The failure probability of the wind energy is obtained as 0.059614 and the failure probability for the intermediate and basic events of the wind energy are represented in Fig. 6.

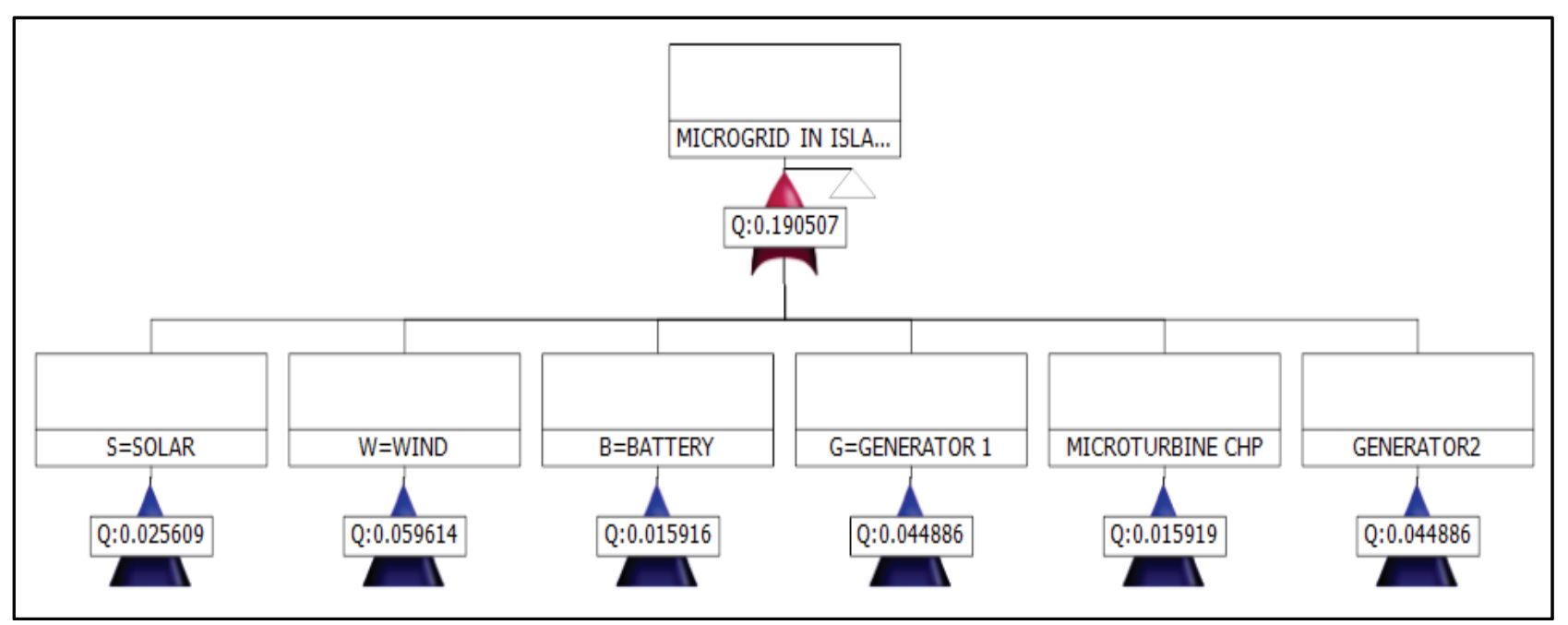

Fig. 3 Fault tree of a microgrid in islanded mode. 


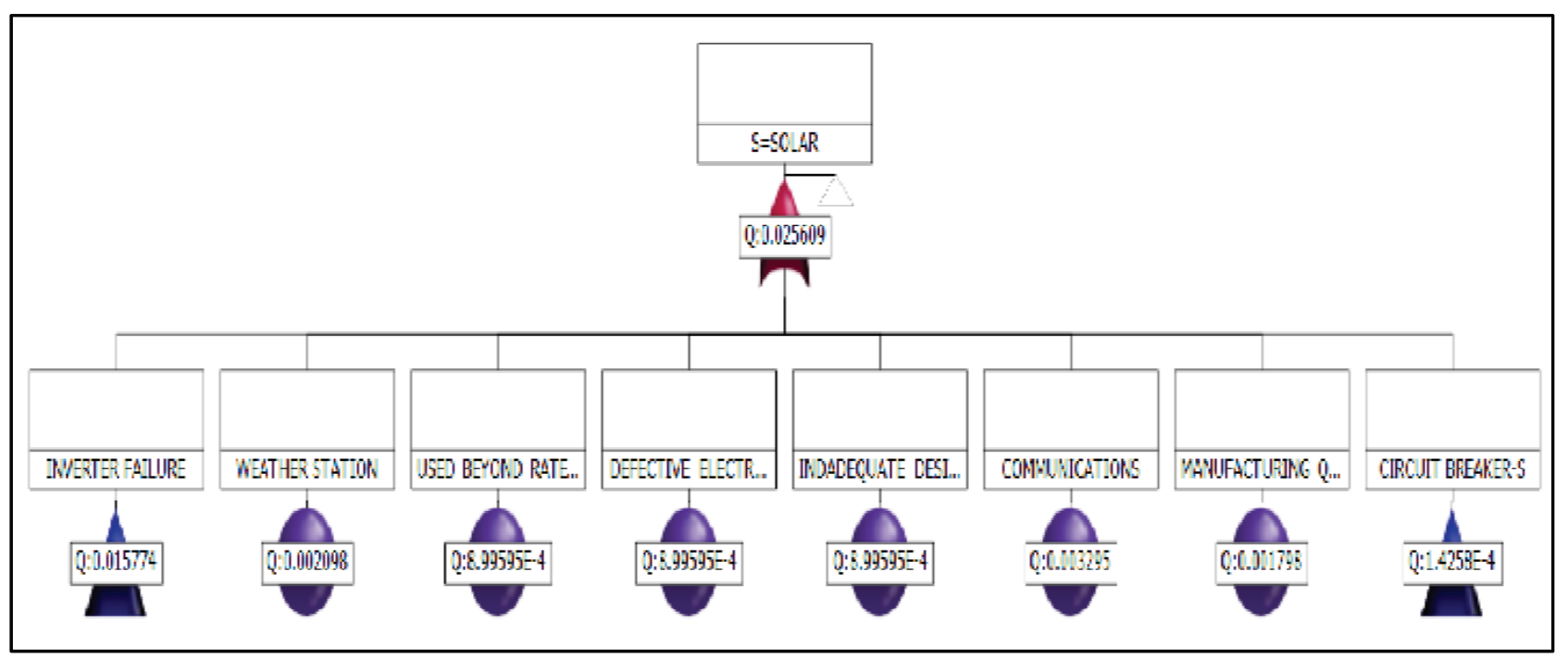

Fig. 4 Fault tree of the solar energy failure causes.

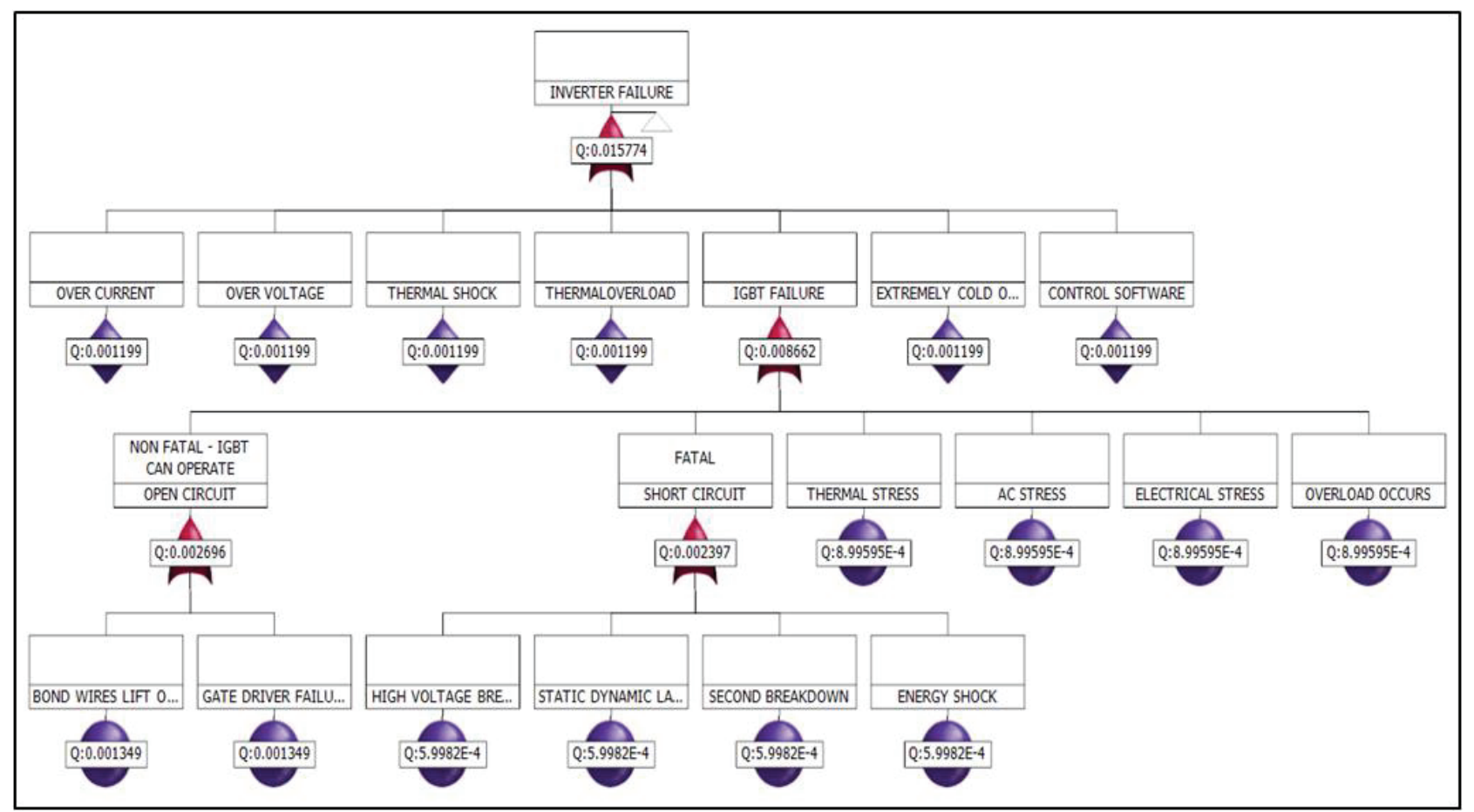

Fig. 5 Fault tree of the inverter failure causes.

\subsubsection{Battery energy storage system}

The failure in a circuit breaker can cause the battery energy storage to fail. The failures in the battery energy storage are circuit breaker across the battery, energetic failures - thermal runaway; thermal abuse-cell internal temperature; cell internal pressure; cell undergoes vent; cell vent gases may ignite; cell may be ejected; electrical abuse - overcharge; over discharge; poor cell mechanism; external short circuit; charging at high current; poor cell electrodes, internal cell faults, inverter, mechanical abuse-shorting between cell electrodes; internal cell faults; damage at electrodes; severe lithium plating, non-energetic failures. The fault tree for the battery energy storage is reperesnted in Fig. 7. The failure probability of a battery energy storage is obtained as 0.015916 and the failure probability for the intermediate and basic events of the battery energy storage are represented in Fig. 7. 


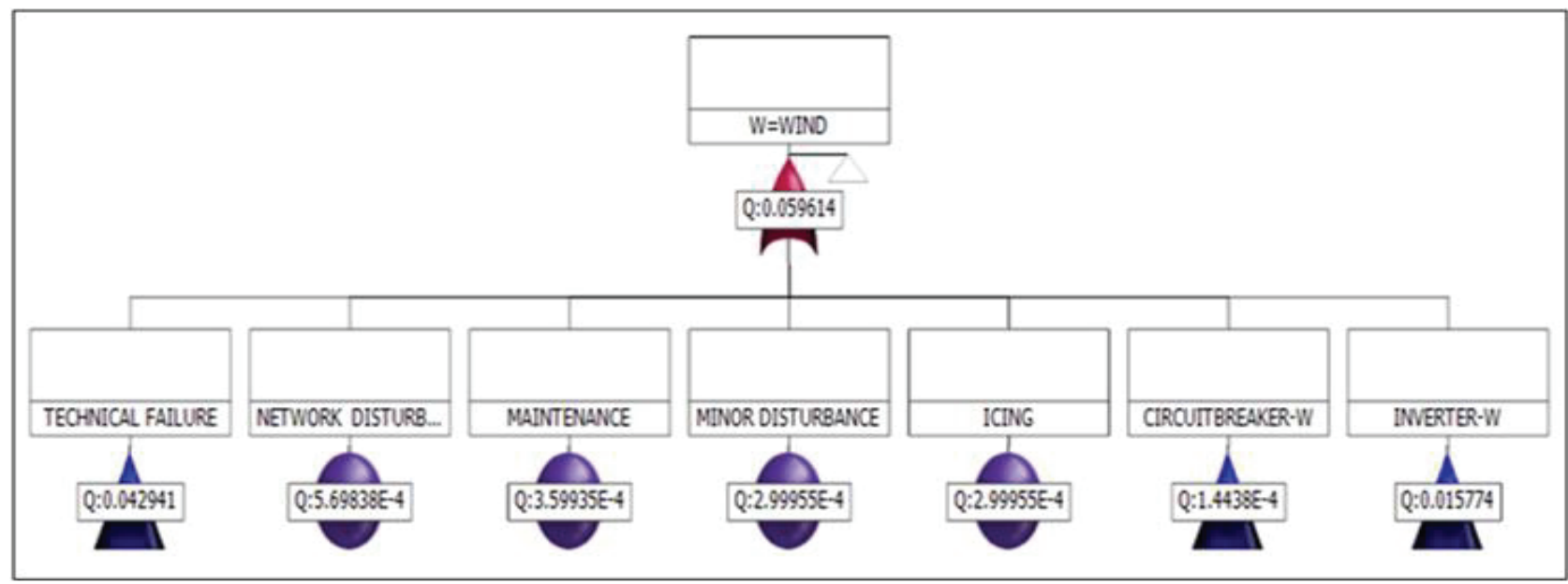

Fig. 6 Wind energy fault tree.

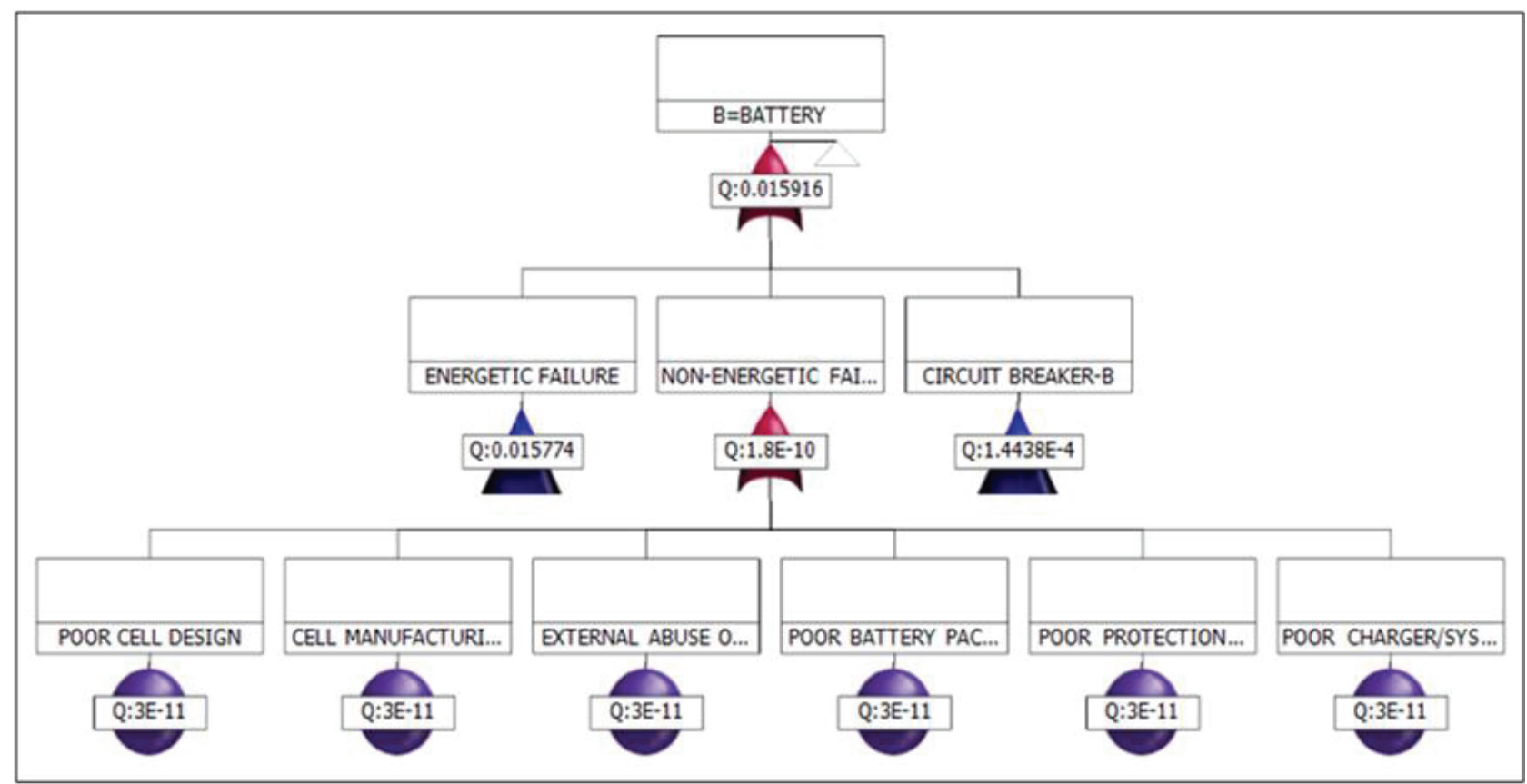

Fig. 7 Battery energy storage fault tree.

\subsubsection{Generators}

Failures in the diesel and natural gas generators, cause to a decrease in the microgrid's power generation which will affect reliability of a microgrid. This will have an impact of circuit breaker operation. The reasons for the generator failures are [17-20]: cooling, engine, exhaust, fuel oil, generator, governor, instrumentation and control, lube oil, starting air, inverter, circuit breaker across the generators. Fig. 8 shows the fault tree generator failures [2]. The failure probability of an inverter is obtained as 0.044886 and the failure probability for the intermediate and basic events of the generator are represented in Fig. 8 .

2.3.1.7 Combine heat and power

Failure of CHP will reduce the microgrid's power generation which will effect the reliability of a microgrid. This will also cause the circuit breaker to fail across the CHP. So, the failure causes of CHP are: gas compressor: disk - high cycle fatigue; low cycle fatigue; blade-high frequency failure due to the resonant vibration; low frequency failure due to the flutter; clashing and clanging due to the surge; stator 


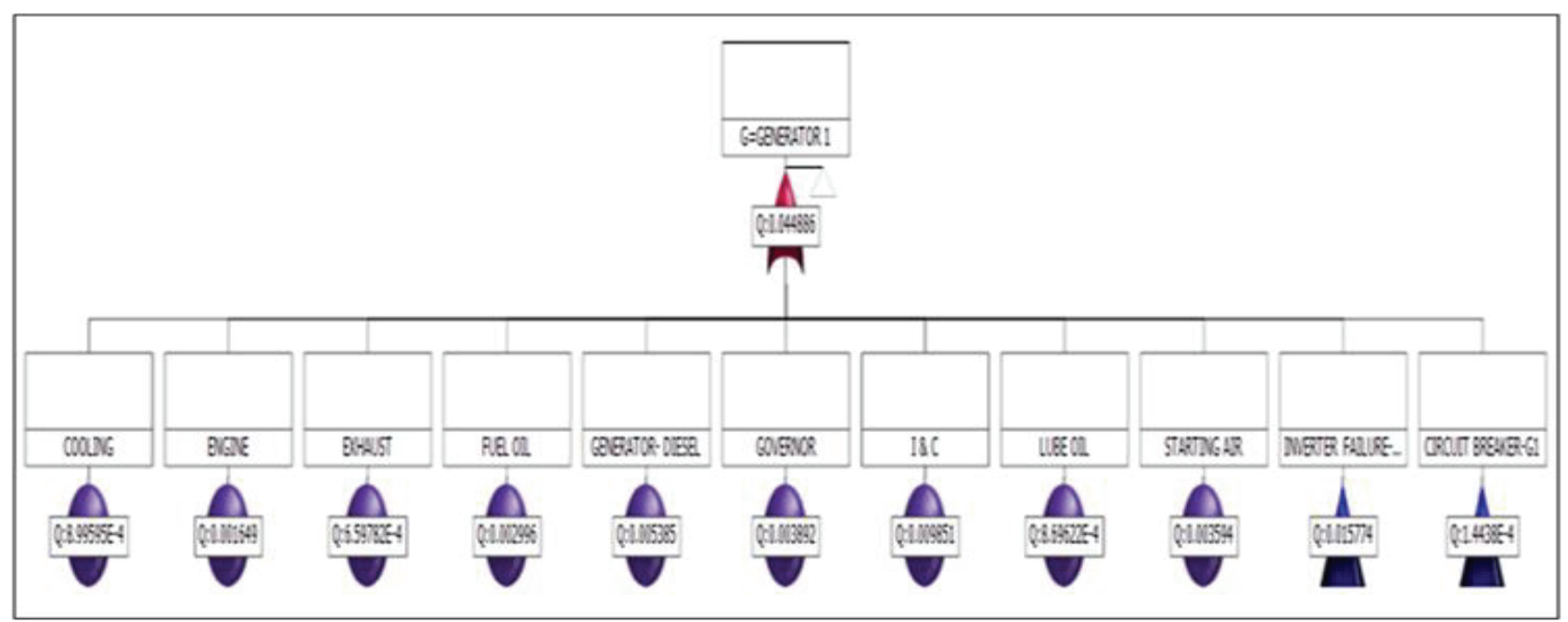

Fig. 8 Fault tree of failure causes of a generator.

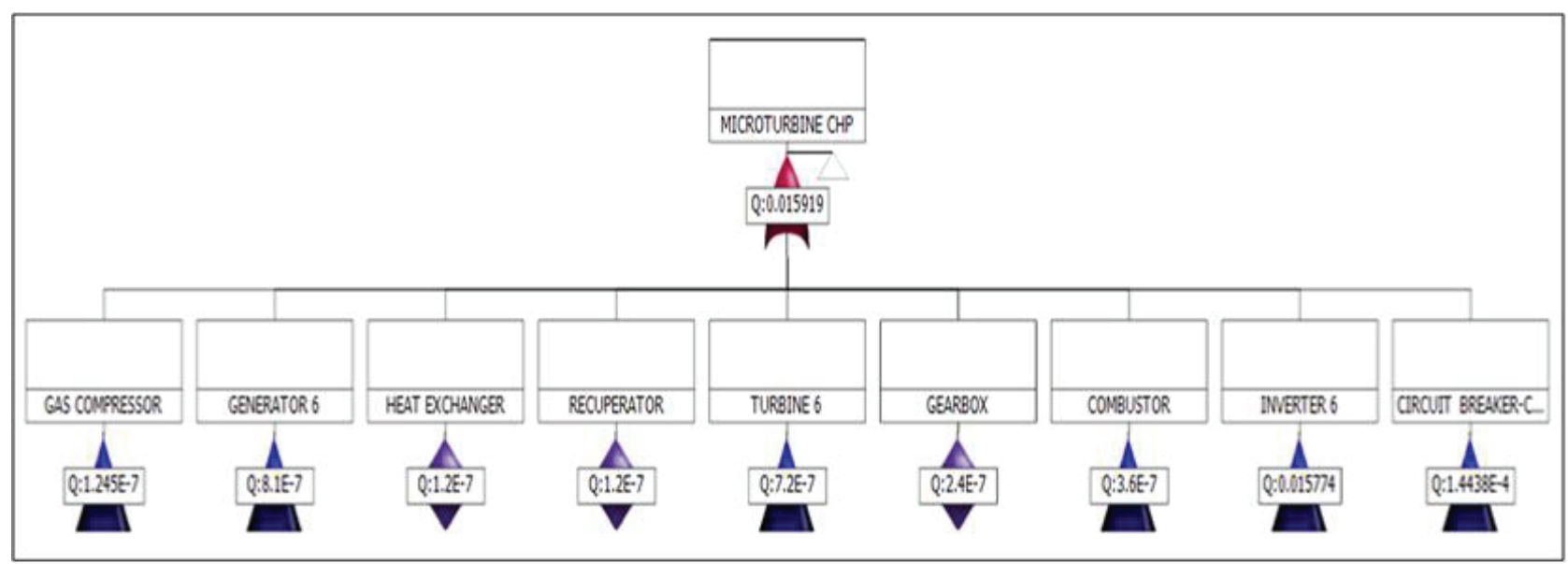

Fig. 9 Fault tree of a CHP micro turbine.

vanes - surge clashing; high freqeuncy failure due to the flutter or resonant vibration; generator, heat exchanger, recuperator, turbine, gear box, combustor, inverter, circuit breaker [16]. The fault tree for CHP failure with a failure probability of 0.015919 is shown in Fig. 9. The failure probability for the intermediate and basic events of the CHP are also represented in Fig. 9.

The fault tree for the turbine failure in CHP with the failure probability of 7.2e-7 is shown in Fig. 10. Using PTC Windchill Solutions software, a fault tree is constructed for a critical load outage using the logic gates. The microgrid failure time is considered as $30,000 \mathrm{~s}$. Then the fault tree is analyzed and the results are obtained as shown in Table 1. From Table
1, the FTA analysis shows that the unavailability = 0.1906 . Thus, the availability is $1-0.1906=0.8093$ or $80.93 \%$; unreliability $=0.1906$. Thus, the reliability is $1-0.1906=0.8093$ or $80.93 \%$ with frequency $=$ 5.4306 and a failure rate $=6.7096$ are obtained [2] The frequency in Table 1 represents the frequency at which the failure occurs for a specific period of time.

Since, availability is the complement of the unavailability.

$$
\text { Availability }=1-\text { Unavailability }
$$

Since unavailability is 0.1906 , availability is 0.8093 . The availability of the critical outage is obtained as $80.93 \%$ [2]. Qualitative fault tree evaluates the basic events combinations which lead to the top event occurrence. 


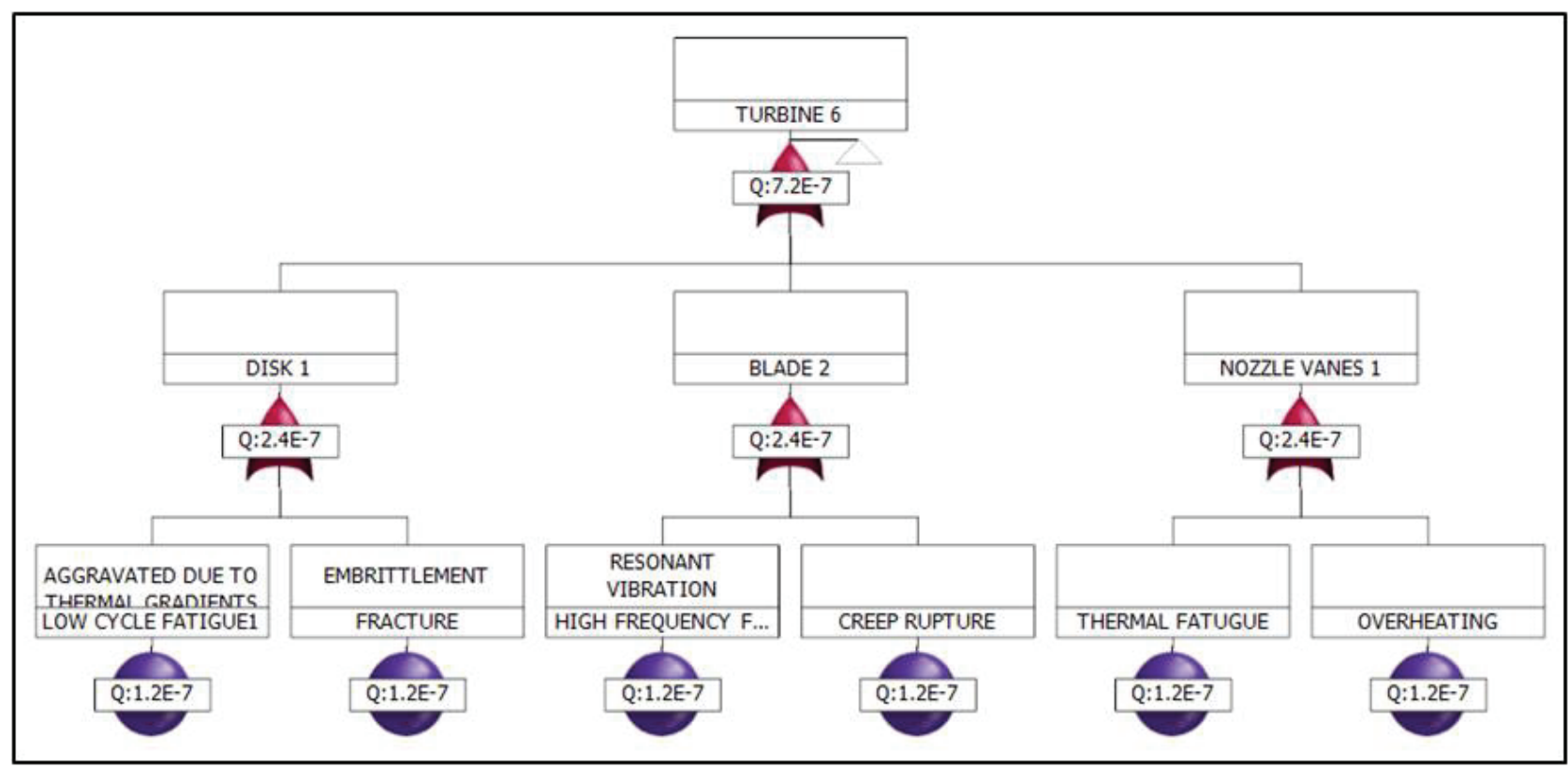

Fig. 10 Fault tree of a turbine failure causes in a CHP micro turbine.

Table 1 FTA results.

\begin{tabular}{lllll}
\hline Time $(\mathrm{s})$ & Unreliability & Unavailability & Frequency $(\mathrm{Hz})$ & Failure rate \\
\hline 0 & 0.010148 & 0.010148 & 6.641584 & 6.709675 \\
3,000 & 0.029874 & 0.029874 & 6.509232 & 6.709675 \\
6,000 & 0.049206 & 0.049206 & 6.379518 & 6.709675 \\
9,000 & 0.068153 & 0.068153 & 6.252388 & 6.709675 \\
12,000 & 0.086723 & 0.086723 & 6.127792 & 6.709675 \\
15,000 & 0.104923 & 0.104923 & 6.005678 & 6.709675 \\
18,000 & 0.12276 & 0.12276 & 5.885998 & 6.709675 \\
21,000 & 0.140241 & 0.140241 & 5.768704 & 6.709675 \\
24,000 & 0.157374 & 0.157374 & 5.653746 & 6.709675 \\
27,000 & 0.174166 & 0.174166 & 5.541079 & 6.709675 \\
30,000 & 0.190623 & 0.190623 & 5.430658 & 6.709675 \\
\hline
\end{tabular}

Using Eq. (2), the minimal cut set probability for the components are obtained as: solar energy: $P_{M C S_{\text {solar }}}=0.90$, wind energy: $P_{M C S_{\text {wind }}}=2.044$, battery: $P_{M C S_{\text {battery }}}=0.574$, diesel generator: $P_{M C S_{\text {gen } 1}}=1.571$, natural gas generator: $P_{M C S_{\text {gen } 2}}=$ 1.571, CHP: $P_{M C S_{\text {chp }}}=1.571$, circuit breaker: $P_{M C S_{C}}=0.0047$ [2]. So, the top event probability of the critical load outage is calculated as in Eq. (3) as:

$$
P_{T O P(C R I T I C A L-L O A D)}=8.237
$$

(1) Importance factors

Importance factors like RAW (risk achievement worth), RRW (risk reduction worth), criticality importance and Fussel-Vesely importance along with the top event probability are included in the FTA.

Risk achievement worth: It helps to maintain the reliability of the system by identifying the components that must be maintained well. It is calculated as given below:

$$
R A W_{k}=\frac{P_{T O P}\left(P_{K}=1\right)}{P_{T O P}}
$$

Thus, RAW for the components in the critical load outage is calculated by using Eq. (4) as follows: Solar energy: $R A W_{\text {solar }}=1.01$, wind energy: $R A W_{\text {wind }}=$ 0.87 , battery: $R A W_{\text {battery }}=1.05$, diesel generator: $R A W_{\text {gen } 1}=0.93$, natural gas generator: $R A W_{\text {gen } 2}=$ 0.93 , CHP: $R A W_{c h p}=0.93$, circuit breaker 
$R A W_{c}=1.12[2]$.

Risk reduction worth: It helps to increase the system reliability by finding the components that are redundant. It is given by Eq. (5) as:

$$
R R W_{k}=\frac{P_{T O P}}{P_{T O P}\left(P_{K}=0\right)}
$$

RRW for the components in the critical load outage is calculated by using Eq. (5) as follows: solar energy: $R R W_{\text {solar }}=1.12$, wind energy: $R R W_{\text {wind }}=1.33$, diesel generator: $R R W_{\text {gen } 2}=1.23$, battery: $R R W_{\text {battery }}=1.07$, CHP: $R R W_{\text {chp }}=1.23$, natural gas generator: $R R W_{\text {gen } 1}=1.23$, circuit breaker: $R R W_{c}=1.00[2]$.

Criticality importance: It helps to calculate the reliability of the components. It is calculated using Eq. (6) as follows:

$$
C_{k}=\frac{P_{T O P}\left(P_{k}=1\right)-P_{T O P}\left(P_{k}=0\right)}{P_{T O P}} P_{k}
$$

Criticality importance for the components in the critical load outage is calculated as follows by using Eq. (6): solar energy: $C_{\text {solar }}=0.11$, wind energy: $C_{\text {wind }}=2.5$, diesel generator: $C_{\text {gen } 2}=0.19$, battery: $C_{\text {battery }}=0.07$, CHP: $C_{c h p}=0.19$, natural gas generator: $C_{\text {gen } 1}=0.19$, circuit breaker: $C_{c}=5.8 \times$ $10^{-4}$.

Fussel-Vesely importance: It signifies all the basic and intermediate components which cause the top event occurrence. It also helps to find the contribution of each event to the top event probability. It is calculated by Eq. (7) as:

$$
F V_{k}=1-\frac{P_{T O P}\left(P_{k}=0\right)}{P_{T O P}}=1-\frac{1}{R R W_{k}}
$$

Fussel-Vesely importance for the components in the critical load outage is calculated as follows by using Eq. (7): solar energy: $F V_{\text {solar }}=0.11$, wind energy: $F V_{\text {wind }}=0.2$, diesel generator: $F V_{\text {gen } 2}=0.19$, battery: $\quad F V_{\text {battery }}=0.71, \quad$ CHP: $\quad F V_{c h p}=0.19$, natural gas generator: $F V_{\text {gen } 1}=0.19$, circuit breaker: $F V_{c}=0[2]$.

(2) Interpretation of the fault tree analysis results

For the evaluation of a fault tree, both the quantitative and qualitative analysis are performed and the results are interpreted further. For this interpretation, boundary conditions and modeling resolutions of the analysis must also be considered. The sensitivity and uncertainty of the fault tree are deduced before the final conclusions.

The entire fault tree is built and analyzed using PTC Windchill solutions. The simulation of the fault tree is performed for 30,000 seconds and the results are obtained. The unavailability's for circuit breaker, microgrid, solar energy, inverter, wind energy, battery energy storage, generators, and CHP are obtained as $1.432 \mathrm{e}-4,0.190507,0.025609,0.015774,0.059614$, $0.015916, \quad 0.04486$ and 0.015919 respectively. Following results are obtained from FTA results as shown in Table 1: unavailability $=0.190623$. Thus, the availability is $1-0.190623=0.8093$ or $80.93 \%$. unreliability $=0.190623$. Thus, the reliability is $1-$ $0.190623=0.8093$ or $80.93 \%$ with frequency $=$ 5.430658 and a failure rate $=6.709675$ are obtained. The failure rate signifies the rate at which the microgrid fails for the entire mission.

Qualitative analysis evaluates the minimal cut sets of circuit breaker across the critical load and also across each energy source: solar, wind, battery, CHP, Generators 1 and 2, and inverter across each energy source. The highest minimal cut set importance is obtained for the wind energy. This shows that the failure occurrence probability in wind energy is high when compared to other components.

The top event probability calculation of a critical load outage is evaluated by quantitative analysis. This indicates the system failure probability. Then the importance measures-RAW, RRW, criticality importance and Fussel-Vesely importance-are calculated. For the critical load outage, the highest value for the RAW is attained by the circuit breaker across the critical load along with the solar energy and battery energy. The probability for the outage of the critical load occurrence is indicated by the RAW. The component with highest RAW should be well 
maintained so that the reliability will not decrease over the time. This also helps to reduce the risk of the system. The wind energy attains the highest RRW value which indicates that the risk of the respective components modeled in their respective events is worth to decrease [6]. Also, the overall risk is reduced. The components which are redundant are identified by RRW. The wind energy is the redundant component which should be maintained well to enhance the microgrid reliability. The reliability of the components are evaluated by the criticality importance. Wind energy has the highest sensitivity of all. Finally Fussel-Vesely importance is calculated to identify the basic and intermediate components which leads to the top event occurrence [2].

\section{Conclusions}

Outage for a critical loadin a microgrid is considered. Using the PTC Windchill solutions, the critical load's reliability and availability is calculated. The fault trees are subsequently analyzed and results are obtained. A graph for unavailability is obtained for a time period of 30,000 seconds. The reliability and availability is $80.93 \%$. The highest value for the minimal cut set importance is obtained for the wind energy, which implies that the failure probability is high for wind energy. Then the evaluation of quantitative analysis is performed for all the components. Also, the importance measures are evaluated and calculated to find the component which are sensitive and at high risk. Among all the components, the circuit breaker across the critical load attains the highest RAW. This implies that the occurrence of a critical load outage is mostly effected due to the circuit breaker across the critical load. So, it must be maintained well to ensure that the reliability will not decrease over the time. The wind energy has the highest RAW value, that is, it must be maintained well as it is at high risk. Next, the criticality importance defines the reliability of the components. Of all the components, wind energy is at high risk and has high sensitivity of all the components. Finally, the Fussel-Vesely importance identifies the basic and intermediate components which leads to the top event occurrence. Thus, it states that the components which are high risk should be maintained well to optimize the reliability.

\section{References}

[1] Andersson, G. et al. 2005. "Causes of the 2003 Major Grid Blackouts in North America and Europe, and Recommended Means to Improve System Dynamic Performance." IEEE Transactions on Power Systems 20 (4): 1922-8.

[2] Ramabhotla, S. 2015. "Energy Management in Microgrids." Ph.D. dissertation, Texas Tech University.

[3] Li, Z., Yuan, Y., and Li, F. 2010. "Evaluating the Reliability of Islanded Microgrid in an Emergency Mode." In Proceeding of the 45th IEEE International Universities Power Engineering Conference.

[4] Ghahderijani, M. M., Barakati, M., and Tavakoli, S. 2012. "Reliability Evaluation of Stand-Alone Hybrid Microgrid Using Sequential Monte Carlo Simulation." In Proceeding of the 2nd Iranian Conference on Renewable Energy and Distributed Generation, 33-8. doi: 10.1109/ICREDG.2012.6190464.

[5] Maleki, B., Gandomkar, M., Maleki, T., and Gandoman, F. H. 2014. "Method of Evaluating Reliability of Microgrids in Island Mode by Using Load Prioritization." In Proceeding of the 19th IEEE Electrical Power Distribution Conference, 76-81. doi: 10.1109/EPDC.2014.6867502.

[6] Jiang, Q., Xue, M., and Geng, G. 2013. "Energy Management of Microgrid in Grid Connected and Stand-Alone Modes." IEEE Transactions on Power Systems 28 (3): 3380-9.

[7] Ma, Y., Yang, P., Wang, Y., Zhao, Z., and Zheng, Q. 2014. "Optimal Sizing and Control Strategy of Islanded Microgrid Using PSO Technique." IEEE PES Asia-Pacific Power and Energy Engineering Conference. doi: 10.1109/APPEEC.2014.7066004.

[8] Lindquist, T. M., Tjernberg, L. B., and Eriksson, R. 2008. "Circuit Breaker Failure Data and Reliability Modelling." IET Generation Transmission \& Distribution 2 (6): 813-20. doi: 10.1049/iet-gtd:20080127.

[9] Janssen, A., Makareinis, D., and Solver, C. E. 2014. "International Surveys on Circuit-Breaker Reliability Data for Substation and System Studies." IEEE Transactions on Power Delivery 29 (2): 808-14.

[10] Flurscheim, C. H. 1985. Power Circuit Breaker Theory and Design, 3rd ed. London: Peter Peregrinus Ltd., Ch.4, 
125-87.

[11] Haarla, L. 2011. "Grid Faults and Components Failures." In Transmission Grid Security: A PSA Approach. London Dordrecht Heidelberg New York: Springer, Ch. 5, 61-77.

[12] C`epin, M. 2011. "Fault Tree Analysis." In Assessment of Power System Reliability-Methods and Applications, 1st ed. London, Dordrecht, Heidelberg, New York: Springer, 15-87.

[13] Margolis, R. 2006. "A Review of PV Inverter Technology Cost and Performance Projections." NREL/SR-620-38771. January 2006. http://www.nrel.gov/docs/fy06osti/38771.pdf.

[14] Fitz, E. 2011. "The Bottom Line Impact of PV Module Reliability." $\quad$ March 2011. http://www.renewableenergyworld.com/articles/print/pv w/volume-3/issue-2/solar-energy/the-bottom-line-impactof-pv-module-reliability.html.

[15] Tundra. "Inverter Troubleshooting." I-TSG-0512-EN. http://www.tundrainternational.com/static/pdf/Inverters Troubleshooting_en.pdf

[16] Ramesh, V., and Saravannan, R. 2011. "Reliability Assessment of Cogeneration Power Plant in Textile Mill Using Fault Tree Analysis." Journal of Failure Analysis and Prevention 11 (1): 56-70.

[17] Wierman, T. E. et al. 2003. "Common-Cause Failure Event Insights Emergency Diesel Generators." NUREG/CR-6819, Vol. 1, INEEL/EXT-99-00613.

[18] Eide, S. A. et al. 2008. "Detailed Study of Emergency Diesel Generator Performance Using EPIX/RADS Database." Present at ANS PSA 2008 Topical Meeting Challenges to PSA during the Nuclear Renaissance Knoxville, Tennessee, American Nuclear Society, LaGrange Park, IL.

[19] Alzbutas, R. 2003. "Diesel Generators Reliability Data Analysis and Testing Interval Optimization." Energetika 4: 27-33.

[20] Samanta, P., Kim, I. S., Uryasev, S., Penoyar, J., and Vesely, W. 1994. "Emergency Diesel Generator: Maintenance and Failure Unavailability, and Their Risk Impacts.” NUREG/CR-5994, BNL-NUREG-52363, Brookhaven National Laboratory Upton, NY.
[21] Kaidis, C. 2013. "Wind Turbine Reliability Prediction-A SCADA Data Processing \& Reliability Estimation Tool.” Uppsala University. September 2013. http://uu.diva-portal.org/smash/get/diva2:707833/FULLT EXT01.pdf.

[22] Stenberg, A., and Holttinen, H. 2010. Analysing Failure Statistics of Wind Turbines in Finland. European Wind Energy Conference, Warsaw, Poland.

[23] Hahn, B., Durstewitz, M., and Rohrig, K. 2006. "Reliability of Wind Turbines Experiences of 15 Years with 1500 WTs." Institut für Solare Energieversorgungstechnik (ISET).

[24] McLaughlin, B. "How to Get High Wind Turbine Reliability." http:/www.lifetime-reliability.com/freearticles/reliabilityimprovement/Wind_Turbine_Reliabilit y_Improvement.pdf.

[25] Fischer, K. 2013. "Reliability and Maintenance of Wind Turbines Challenges and Perspectives." http://www.gaccmidwest.org/fileadmin/ahk_chicago/201 3_EVENTS/2013_GRP_Windenergie/PPTs_Wind_Conf erence/02_Fischer.pdf.

[26] Wildiers, Z. et al. 2009. "Operation and Maintenance Cost of Wind Generated Power." http://www.wind-energy-the-facts.org/operation-and-mai ntenance-costs-of-wind-generated-power.html.

[27] Nivedh, B. S. 2014. "Major Failures in the Wind Turbine Components and the Importance of Periodic Inspections.' http://www.dewi.de/dewi_res/fileadmin/pdf/papers/Wind Insider_November_2014.pdf.

[28] "Fault Tree Diagram-Edrawsoft." http://www.edrawsoft.com/fault-tree-diagram-software.p hp.

[29] Wiensan, T. E. 2003. "Common-Cause Failure Event Insights Circuit Breakers.” NUREG/CR-6819, Vol. 4 INEEL/EXT-99-00613.

[30] Tulkoff, C. 2012. "Reliability Challenges for Solar Electronics-dfr Solutions." http://www.dfrsolutions.com/ uploads/courses/SPI2012.pdf.

[31] Roos, F., and Lindahl, S. "Distribution System Component Failure Rates and Repair Times-An Overview." http://citeseerx.ist.psu.edu/viewdoc/download? doi=10.1.1.133.2539\&rep=rep1\&type=pdf. 